\title{
Construction and Exploration of Collaborative Cloud Platform for Practical Teaching--In the Perspective of the Practical Teaching Sharing Platform of Virtual Simulation
}

\author{
Lu Minrong ${ }^{1,2, a}$, Pan Yan ${ }^{2,3, b, *, ~ a n d ~ W u ~ H a i d o n g ~}{ }^{3, ~ c}$ \\ ${ }^{1}$ School of Accountancy of Fujian Jiangxia University, Fuzhou, 350108, China \\ ${ }^{2}$ Finance and Accounting Research Centre Fujian Province Philosophy Social Science Research Base, Fuzhou, \\ 350002, China \\ ${ }^{3}$ School of Economics \& Management of Fuzhou University, Fuzhou, 350116, China \\ aluminrong163@163.com, bfzdxpy@163.com, 'ywhd@fzu.edu.cn
}

Keywords: Experimental teaching; Collaborative cloud; Virtual simulation; Sharing platform; Shared strategy

\begin{abstract}
Looking back to the practical teaching in higher education in recent years, practical teaching has gradually shifted from purchasing specialized software and increasing university-enterprise cooperation projects to establish virtual stimulation teaching platform in order to improve the effect of practical teaching. However, the cost of the development of virtual simulation platform is high and the sharing degree between colleges and universities is low. Moreover, the sharing mechanisms advocated by colleges and universities are incomplete. In this paper, the sharing of practical teaching platform of virtual simulation is taken as a starting point, and it illustrates key technology, platform architecture and sharing strategies for practical teaching cloud platform. This platform integrates the exclusive resources centered on courses, virtual classroom, practical projects from colleges and universities into massive social education resources in the fields of discipline, major group. Taking the practical teaching sharing platform of virtual simulation of Fuzhou university as an example, the virtual teaching cooperative environment is constructed, which shows that the platform is feasible and effective and sharing within and outside the school as well as across regions has had a good teaching effect.
\end{abstract}

\section{Introduction}

Experimental teaching is a significant component in higher education. It plays a crucial role in improving the students' practical abilities and innovation capacities. In other words, the key to develop the students' abilities to resolve practical problems with theoretical knowledge and skills lies in experimental teaching[1]. Currently, Chinese colleges and universities have generally recognized the trend of online education and the significance of practical teaching, and have been exploring a natural experimental teaching and management system that can help not only impart the theoretical knowledge to students in a systematic manner, but also integrate the practical skills with classroom teaching; besides, online platforms and various technologies, such as Computer Multimedia, Internet and Virtual Simulation, have been introduced to improve the training Mode of School-Enterprise Cooperative talents and to lift the quality of experimental teaching[2,3]. With the advancement of MOOC, Flipped Classroom, Big Data Technologies and Learning Analysis Technologies, universities and colleges are facing a crucial moment for educational innovation and breakthrough. To achieve teaching goals, helping students to master a high level of practical skills has been a focus in experimental teaching.

As the information technologies advance, information tools such as multimedia technologies, tabloid, smart phones and Blackboard platform, have been rushing into classrooms as an effective tool to assist the teachers. Education reforms of experimental teaching among universities both in 
China and abroad are shifting from information-based teaching tools to Internet technology-based teaching mode[4]. Take the Massachusetts Institute of Technology, its Open Media Lab is a cross-disciplinary lab that effectively blends technologies, media and design; and its MOOC-based teaching mode has also displayed the development tendency of Internet + . Relevant researches including Alcom have conducted analysis over the influence of online teaching platform on the overall education industry[5]. Scholars like Chen Chao, Lv Guodong and Xiu Baoxin have also discovered that most online cooperation focus more on learning resource management and learning course development. Liu Xiaojing and Zhang Jianping also found that online teaching platforms can enable effective integration of in-classroom teaching with out-of-classroom activities, which expands the time and space of teaching and provides a valuable reference for teaching reform[6]. Besides, in designing and realizing online teaching platforms, apart from teaching goals and contents, students' needs have also been fully taken into account[7,8]. In recent years, the Internet + Education has generated various teaching modes. In particular, since the Teaching Center of Vanderbilt University defined the concept of Flipped Classroom, a overturn of traditional teaching, relevant researches become increasingly diversified. With the guidance of Flipped Classroom, students' academic performance are improved, their learning initiatives are promoted and learning practices is also turning into a better direction. Many experts predict that the Flipped Classroom will be widely used in high education in the future[6,9]. As for the Internet + Education in China, with the guidance and supports from governments, such as the establishment of Demonstration Centers of Experimental Teaching and the sharing of teaching facilities (Zhang Ruilin),taking the virtual simulation experiment as a cutting point, the MOOE(massive open online experiments)-based teaching platform has been proposed (by Cui Guanxun and Xiong Jianping) [10,11].

To sum up, researches on teaching platforms such as MOOC and Virtual Simulation have been focused on the reform and experiment of traditional teaching mode and platforms. The virtual simulation experimental teaching(VSET) platforms lack studies about integrated sharing platforms and sharing mechanisms; and analysis over the effects of shared teaching mode is also rare. On the basis of investigation and analysis over the situation of construction of demonstration center of VSET in colleges and universities in Fujian Province and the implementation and sharing situation of VSET platforms, by integrating and extending the information resources of VSET in colleges and universities in Fujian to other provinces, the practical teaching cloud platform is established to form a virtually interconnected online learning sharing platform connecting colleges and universities across China and to explore a strategy of platform sharing.

\section{Present situation of the construction of VSET sharing platform}

To promote the sharing and informationization of higher education resources, the Ministry of Education has established the China Open Education Resource Sharing Association in 2002. To enhance the sharing of educational resources, the association has organized seminars on the cooperation of educational resource sharing in China and abroad in Beijing, Shanghai and Xi'an respectively in 2002, 2004 and 2006. Conventional sharing practices of higher education resources have been more on policy level; the management mechanism of resource sharing among universities and colleges is incomplete; procedures are complex; and the sharing level of site resources is low; to put it simply, the conventional resource sharing is difficult to implement.

\subsection{Virtual Simulation Technology}

Virtual Reality (or VR) is a comprehensive integrated technology emerged in the 1980s, involving Computer Graphics, Human-Machine Interaction, Sensor Technology and Artificial Intelligence. It intends to create an artificial environment of three-dimensional information, or virtual environment, that comprises computer hard-wares, soft-wares and various sensors, to simulate the objects and environments in the real world or even those that do not exist. By engaging into this environment, people can instantly acquire an immersive experience and interact with the virtual world through in-person operation. The virtually simulated experimental environment can not only enable 
experimenters to carry out experiments that are not feasible in real world, but also lift the experience of experimental environment. However, currently the virtual simulation are mostly developed on the basis of virtual reality technology, the development cost of which is quite high. As the simulation effects improves, the development cost will increase significantly and the cost of subsequent customized development will also surge accordingly. Hence, the benefit sharing of virtual simulation becomes urgent, the cost that the government invest into education will drop as the sharing become more generalised $[12,13]$.

\subsection{Background of building of VSET}

As part of the "10-year Development Plan for the Educational Informationization", China's Ministry of Education launched the construction of National Experimental Teaching Center of Virtual Simulation to introduce the virtual simulation technology to undergraduate education[14].Lei Chaozi from the Science and Technology Department of the Ministry of Education pointed out that China's educational informationization is moving from the 1.0 Era featuring developing exclusive resources for education to the big resource-oriented 2.0 stage to bring the educational informationization towards an integrated development direction[15]. The virtual simulation experiment teaching is an important content in the construction of Higher Education Informationization and the Experiment Teaching Demonstration Center, and also is the result of the deep fusion of the discipline specialty and information technologies. Scholars like Zhang Xinxiang and Huang Kai discovered that the distribution pattern of Experiment Teaching Demonstration Center has presented a balanced layout with special focus on regional deployment, taking into full account of disciplines distribution and development of colleges and universities. The virtual simulation experiment teaching is mainly characterized by the sharing of educational resources on the internet, though, with a small scale that is merely limited to on-campus zone. Therefore, this study proposed a plan for the integration of informationization resources of VSET to drive the transformation from developing education-exclusive resourced within campus to sharing the bigger educational resources in the society, and to build the sharing platform to advance the sharing level of VSET platforms and the informationization level of experimental teaching, so that the educational informationization can develop in a integrated manner.

\subsection{The present situation of sharing of VSET plarforms}

The sharing of VSET platforms is mainly led by the government. Despite some policy guidance and supportive measures for implementation from colleges and universities, its operation was not quite smooth as expected. At the government level, it has been specified that VSET platforms must be operated for social sharing, and that the same VSET platform cannot be developed in the same region. However, due to the lack of effective inter-school sharing mechanism, most sharing operation have been stuck at a superficial level. When approving the construction of VSET demonstration centers, education departments of various provinces required that universities and colleges must submit websites of VSET-related platforms that are accessible to the whole society. However, such websites has been found neither in the approval's public announcement nor in the officially publicized documents.in June of 2018, the Ministry of Education published the first batch of National VSET projects on the National sharing platform of VSET projects (experimental space: www.ilab-x.com), which significantly benefits the collective management and provides a good starting point; yet none of the projects released any relevant websites of platforms targeting the whole society and additional search much be conducted if there is a need for reference or learning. Moreover, few universities and colleges displayed those VSET platforms on its website's homepage that have helped resolve management issue of Internet + Education; the VSET platforms have been mostly placed in the Column of Experimental Teaching that is usually managed by the Academic Affairs Office or by the specially-built Experimental Teaching Center Department. Additionally, the arrangement of these columns is not uniform, making it difficult to search and find; more universities and colleges are choosing to place them on their subordinate school's websites that normally have no site search function. For those unfamiliar with the management of universities' subordinate organizations, 
searching can be even more inconvenient. In an era of data explosion, a shortage of quick access and sharing mechanism can bring the Internet + Education into dilemmas.

\section{Design proposal of VSET sharing platforms}

The collaborative cloud platform for practical teaching was established taking an F University's VSET sharing platform for economic management as the prototype. F University possesses multiple Experimental Teaching Demonstration Centers of both national level and provincial level. Its economy and management discipline has a complete subject coverage and solid foundation, which make its VSET platforms more exemplary and influential. Its VSET platforms include Comprehensive Laboratory of E-commerce, ERP Comprehensive Laboratory, Enterprise Operating Simulation Laboratory, Financial Engineering Laboratory, Security Trading Simulation Laboratory and Banking Business Simulation Laboratory. At the same time, it has also formed a integrated industrial-teaching resource that combines scientific researches and educational researches, which has helped it deliver highly professional and practical compound graduates for the region and the National Economic Management Federation.

\subsection{Environment design}

With Internet+ Technologies and Big Data Technologies, the VSET demonstration centers' experimental teaching platforms can establish real-time update dynamic sharing database according to varied regions, categories, grades and demands. The university education resource integration plan can be developed on the basis of VISIO STUDIO C\#（2015）+SQL SERVER (2012) to build and display the university education resource public service platforms (the VSET sharing platforms) within the province on the internet platforms. The environment design is shown in Fig. 1. The educational resources on VSET platforms of various universities and colleges will be shared on the regional public service platforms, so that teachers and students from various universities and colleges can share the educational resources at anytime and anywhere, and that other quality educational resources can be supplied and shared.

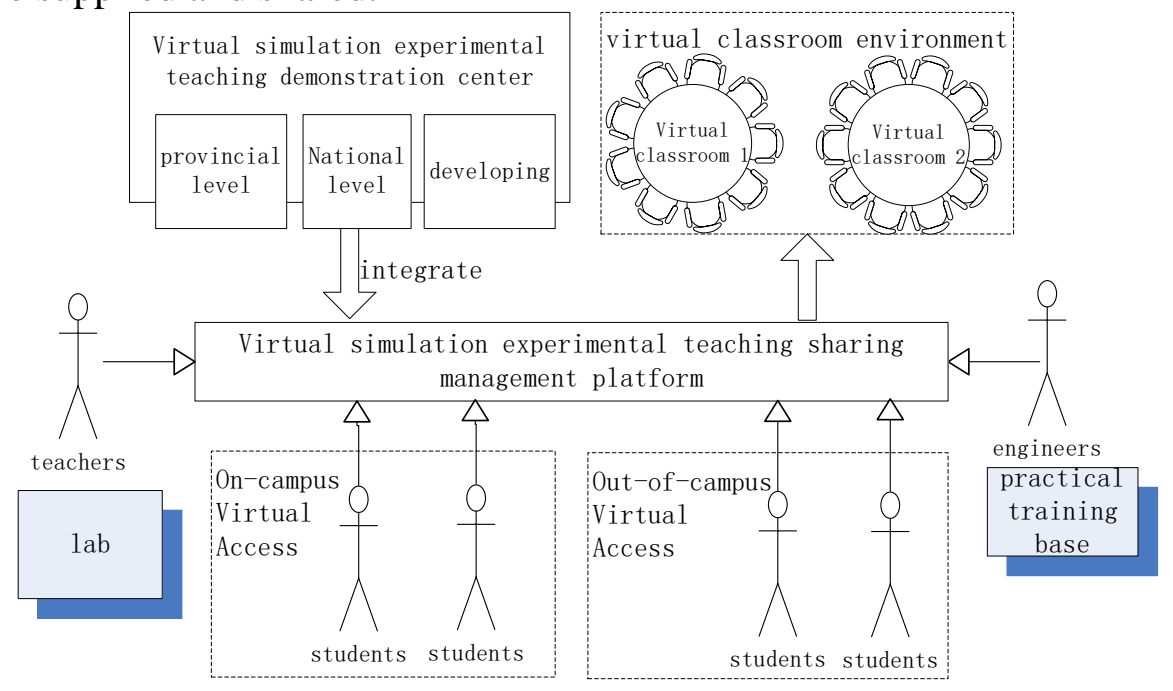

Fig. 1 Virtual Teaching Cooperative Environment

The design of cooperative environment of virtual teaching managed to integrate the VSET platforms of various levels, both national level and provincial level. It enables a virtual classroom for experimental teachers and training engineers on the sharing platform to be accessible for both on-campus and out-of-campus visitors, converting the special resources exclusive for universities into a bigger educational resource for the whole society. Through collective sharing, the VSET resources can be accessed with browsers among universities without any time and space limitations, which both greatly increases the teaching facilities'use rate and makes the teaching and learning activities easier than ever. In addition, the staggering time arrangement and mutual recognition of 
academic scores can also be seen as a starting point for a new educational reform. Establishing a Internet+based VSET sharing platform can not only allow convenient, interactive and shared learning experiences, but also advance the organization, integration and improvement of experimental teaching; it can further help the academic construction and innovative entrepreneurship to fulfill their functions and exemplary roles in the Experimental Teaching Demonstration Centers (including the provincial VSET demonstration centers) in a wider, deeper and extensive manner.

\subsection{Data acquiring and algorithm}

VSET platform entries varies from universities to universities. What search engines like Baidu.com can give are mostly portals of suppliers and advertisements. It is difficult to access the platform from government websites and school websites. On the other hand, in exploring experimental teaching, such activities as platform upgrades, adding new VS experimental projects and server replacement can cause changes to the platform websites. Therefore, at the initial stage of building the cooperative cloud platform, information such as VSET platform websites, its disciplinary category, project level (national or provincial) and year of project establishment must be collected; in the meanwhile, routine inspections must be carried out to check the websites' effectiveness and whether the platforms' levels have changed. In the data collecting process, each page has a HTML tag and corresponding contents; the data sources should be websites of the Ministry of Education, educational departments of various provinces and relevant colleges and universities that have uniform HTML tags; besides, python web-crawler will be used. Generally, the data acquiring process can be divided into 2 categories:

In the first category, information are acquired from government websites (Ministry of Education, Education departments of various province) through searching the key words- Virtual Simulation. The pages' HTML tags will be matched and contents will be acquired and cleansed.

The second category intend to acquire information on school web-pages, with names of VSET as data themes. By this method, platform names need to be obtained from national VSET demonstration centers and will be used to identify themes, which has a high accuracy and small workload for data cleansing.

In the data collection process, the data on the corresponding pages of the above 2 categories are semi-structured data. Considering that these pages' HTML tags are fixed, DOM tree can be obtained though web structure analysis. By traversing the DOM tree, elements related to relevant themes can be acquired. To facilitate subsequent data acquisition and maintenance, DOM set bank should be built. The DOM set bank includes web-pages of governments and schools and their corresponding DOM tree. The database's table relationships are shown in Fig.2.

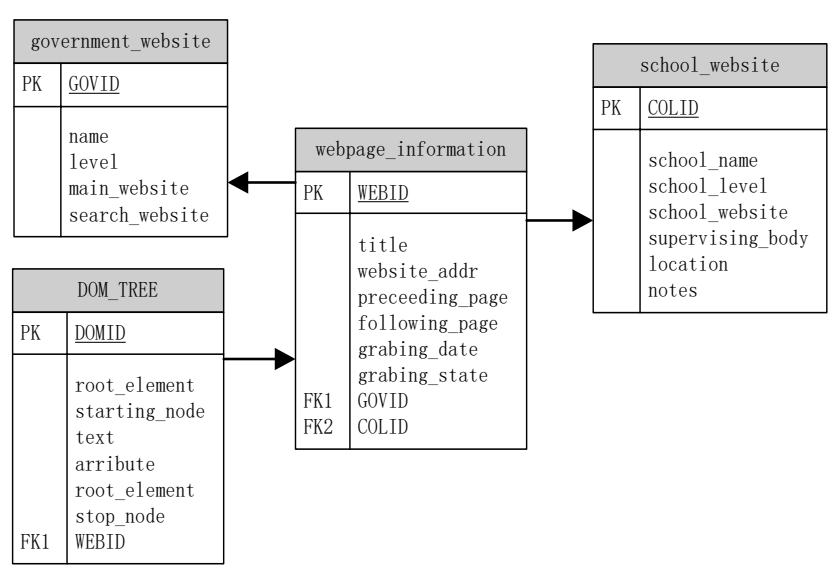

Fig. 2 Table Relations of DOM Set Bank

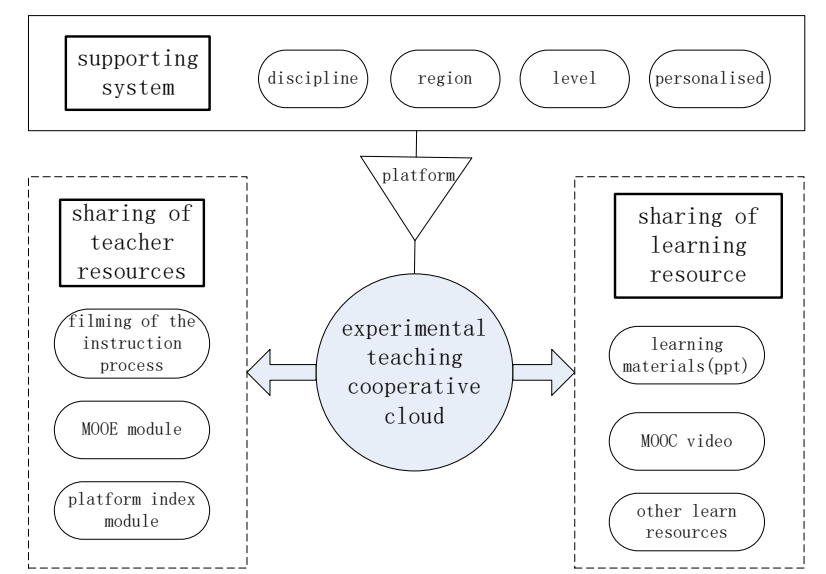

teaching cooperative cloud

Fig. 3 Functionstructure of virtual simulation

Algorithm grab with Scrapy (Python Crawler Frame) is as follows:

yield Request(url, callback=self.parse) \#url for governments and schools website mentioned 
above

def parse(self, response)

hxs = HtmlXPathSelector(response) \# create a query object establish query object

items=hxs.select('//div[@class="node info"]/div') \#select fill in the node of query object

for $i$ in range(len(items)): \# the node in the corresponding DOM tree

item[' title'] = hxs.select('//div[@class="w_conCenter"]/ul/h1[1]/text()').extract()

\# Or obtain relevant document content and attachment,e.g. item['file content'] ,item['relevant attachment']

\subsection{Function design and effect demonstration}

In terms of School-Enterprise cooperative cloud, the quality of hardware and software resources varies from universities to universities. Parts of the experiments lack supports from soft-wares. With sharing platforms, virtual simulation experimental projects and courses can be produced. The regional sharing of VSET platforms has a certain coverage scope, which can help build a Visually Interconnected online learning sharing platform, in order to form a platform sharing mechanism that integrates the virtuality and reality, on-campus and out-of-campus, online and offline, and that compensates the weakness with strength. The VSET platforms include 3 function modules, shown in Fig.3.

Experimental teaching sharing platform mainly includes Experimental Teaching Demonstration Center, Virtual Simulation Teaching Demonstration Center (including the VSET Platform) and Virtual Simulation Experimental Projects; resources include Power point, Videos (for teaching and guidance) and MOOE modules etc. The implementation effects are shown in Fig.4. Teachers and students can choose their desired resources based on the discipline features. Each VSET platform has a corresponding websites that enable access to the website contents. Account names can be obtained from relevant universities for login if required. Generally, universities are eager to share their VSEP platforms to acquire more feedback, in order to improve the platform's stability and use rate.

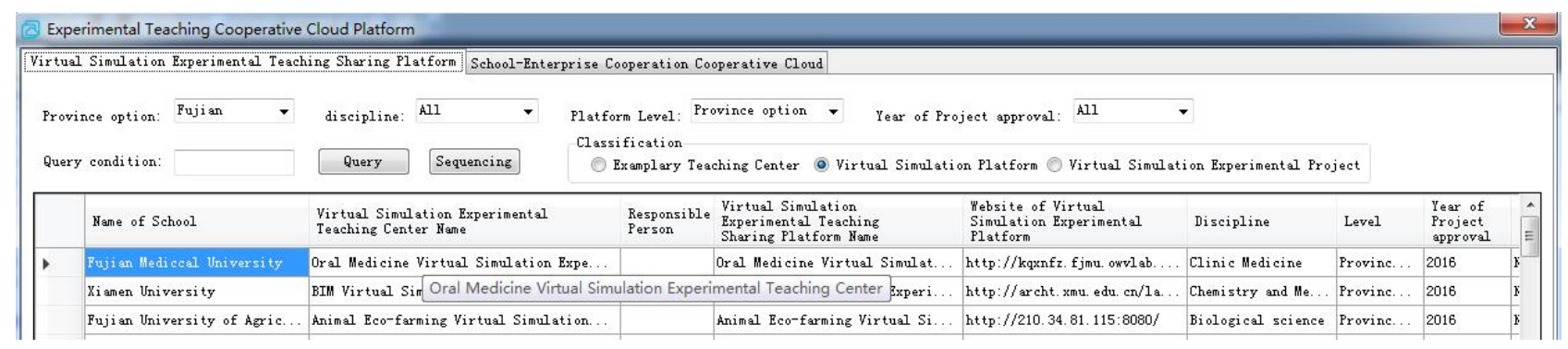

Fig. 4 Rendering of Implementation of the Cooperative Cloud Function

\section{Sharing strategy of VSEF platforms}

The experimental teaching demonstration centers, VSET platform deployment and teaching resources like Power points and videos are mostly deployed on school servers. Although the servers' operation period can reach $7 * 24$ hours, time beyond teaching has a high vacancy rate. The integrated approach of sharing platform resources can not only convert the university-exclusive educational resources into bigger social educational resources, bot also can life the educational facilities's use rate. With supports of sharing policies for relevant educational resources, universities and colleges should cooperate proactively in implementing and exploring the operability of sharing educational resources to give full play of the exemplary role of university VSET demonstration centers and to build a experimental teaching cooperative cloud platform through mutual recognition of academic scores, platform sharing and resource compensation. The building of sharing platforms is carried out taking into account of discipline distribution and subject sets; and the platform contents is also enriched with practical course resources and virtual simulation experimental projects as the carrier. The implementation of sharing follows the route as shown in Fig. 5. 


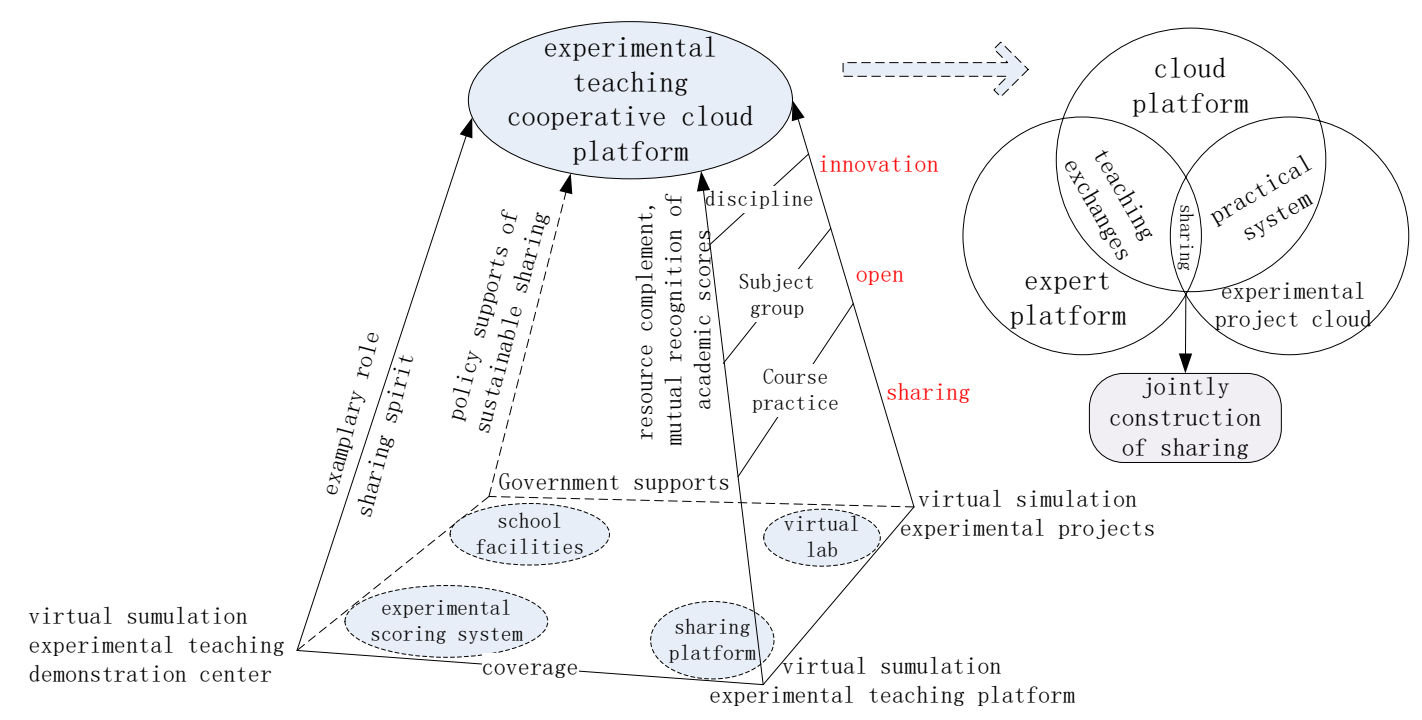

Fig. 5 Implementation of cooperative cloud sharing

\subsection{Government level}

From the government level, first, policy measures to guide and support sharing and to encourage mutual recognition of academic scores between universities should be continued to bring sharing level and use rate into mid-term appraisal and acceptance process of relevant platforms and projects; second, information about relevant experimental teaching platforms should be released on websites of education-related authorities, such as provincial education department, during the process of project approval and release of mid-term appraisal results; meanwhile, governmental functions should also be used to regularly collect, sort and analyse information regarding the sharing situation of resources on VSET platforms and universities, such as boutique courses and innovative start-up projects, in order to further promote the sharing of educational resources and balance the regional distribution of educational resources. For example, in 2017, the Ministry of Education released the list of colleges and universities; by adding a column displaying websites of colleges and universities, it would make it easier to accurately understand the information of universities and reduce the influence of fake websites.

Additionally, in promoting the construction and sharing of educational resources, government authorities should also provide muti-layered data indicators for evaluation that are specific and operational enough to properly assess the sharing performance, such as person visits, number of on-campus accounts and out-of-campus account, effects of joint construction etc. In terms of policies for sharing of educational resources, sustainability should be taken as a supporting role to optimize the sharing strategies of VSET platforms, in order to offer a macro-guidance and develop more sharing space at the school level.

\subsection{School level}

Therefore, from the school level, efforts should be made to establish a standard of mutual recognition of acamemic scores and relevant supervision and appraisal system to give full play of the users'initiatives in the platform sharing process. Secondly, universities should apply collective management for the VSET resources to display the resources in a more friendly manner, such as add a quick access to the university's web-page or add information of other schools on its own VSET platforms. In the case of F University, it sets a column on its website displaying information about the experimental teaching centers of the Capital University of Economics and Business and the Xiamen University, and offers test accounts for these shared platforms, in order to facilitate the learning activities of teachers and students, forming a joint university platform group of same disciplines and experimental project cloud; the VSET should be dominated by colleges and universities and should display specialized links that are more commonly used and more effective for the teachers, for example, the F University set up a virtual classroom and teaching points with supportive policies, as 
shown in Table 1:

Table 1 sharing form s and relevant websites of F University

\begin{tabular}{|c|c|c|c|}
\hline $\begin{array}{l}\mathrm{N} \\
\mathrm{O}\end{array}$ & Sharing form & $\begin{array}{c}\text { Teacher } \\
\text { names }\end{array}$ & Relevant websites \\
\hline 1 & $\begin{array}{l}\text { Teachers' } \\
\text { teaching points }\end{array}$ & $\begin{array}{c}\text { Liu } \\
\text { Xiaocha } \\
\text { o }\end{array}$ & $\begin{array}{l}\text { http://jgsyzx.fzu.edu.cn/Content.aspx?id=07ab3746-57 } \\
\text { 43-471f-bb1f-cfc4464b6383 }\end{array}$ \\
\hline 2 & $\begin{array}{l}\text { Teachers' } \\
\text { teaching points }\end{array}$ & $\begin{array}{l}\text { Yang } \\
\text { Lixi }\end{array}$ & $\begin{array}{c}\text { http://jgsyzx.fzu.edu.cn/Content.aspx?id=c9d90b72-84 } \\
\text { 87-4be1-b121-476f83f7ebc0 }\end{array}$ \\
\hline 3 & Virtual classroom & $\begin{array}{l}\text { Chen } \\
\text { Chaohui }\end{array}$ & $\begin{array}{c}\text { http://jgsyzx.fzu.edu.cn/Content.aspx?id=eca17d66-7a } \\
\text { be-4cf1-aaa6-125045c5d3f2 }\end{array}$ \\
\hline 4 & Virtual classroom & $\begin{array}{l}\text { Lin } \\
\text { Xiaoji }\end{array}$ & $\begin{array}{l}\text { http://jgsyzx.fzu.edu.cn/Content.aspx?id=ef82a4dd-d63 } \\
\text { f-479d-8ebc-3707600a173c }\end{array}$ \\
\hline 5 & Virtual classroom & $\begin{array}{l}\text { Wu } \\
\text { Haidong }\end{array}$ & $\begin{array}{l}\text { http://jgsyzx.fzu.edu.cn/Content.aspx?id=10cce1b3-a3a } \\
\text { e-48e4-bdfc-a0fe54bf2d7d }\end{array}$ \\
\hline
\end{tabular}

\subsection{Advices for the platform}

The VSET platform of colleges and universities has resolved the management issue facing the Internet+ Education, by integrating the virtuality with the reality, through multiple teaching methods that combine the online approaches (VSET platforms) with offline resources (Labs), associations(organizations initiated by students) with competitions (instructed by teachers), practical training with innovative entrepreneurship. As a advice, it is suggested that these methods are incorporated into universities' VSET platforms to enrich the platforms' functions; secondly, experimental teaching reform should be deepened from the level of experimental projects, course system, experimental platforms, teaching systems and management and service systems to explore a optimized lab and experimental teaching platforms, in order to let the reality and virtuality mutually reinforced and complementary, and to combine the discipline with the entrepreneurship, experimental teaching with scientific research, and to enrich the platform's significance, for example, the F University's VSET sharing platform includes 32 independent experimental teaching platforms, 28 mixed experimental platforms, 25 independently developed teaching platforms, 25 independently developed muti-functioned service and management platforms etc. In Table 2 shows part of its platform components.

Table 2 Research Platform list of F University

\begin{tabular}{|c|c|c|}
\hline Platform type & Platform name & Platform website \\
\hline $\begin{array}{l}\text { independent } \\
\text { experimental teaching } \\
\text { platform }\end{array}$ & $\begin{array}{l}\text { Virtual simulation lab for business operation analysis } \\
\text { Virtual simulation lab for financial practices } \\
\text { Practical training platform for financial analysis }\end{array}$ & $\begin{array}{l}\text { http://jyfxyc.ifzu.cn } \\
\text { http://cnsw.ifzu.cn } \\
\text { http://cwfxsx.ifzu.cn }\end{array}$ \\
\hline $\begin{array}{l}\text { mixed } \\
\text { platform }\end{array}$ & $\begin{array}{l}\text { Experimental platform for B2C E-commerce } \\
\text { Experimental platform for B2B E-commerce } \\
\text { Experimental platform for Smart business }\end{array}$ & $\begin{array}{l}\text { http://gyb2c.ifzu.cn } \\
\text { http://gyb2b.ifzu.cn } \\
\text { http://gybi.ifzu.cn }\end{array}$ \\
\hline $\begin{array}{l}\text { independently developed } \\
\text { teaching platform }\end{array}$ & $\begin{array}{l}\text { National classic course of Accounting Principles } \\
\text { Provincial classic course of marketing } \\
\text { Key project course of Advanced Financial Accounting } \\
\text { for postgraduate }\end{array}$ & $\begin{array}{l}\text { http://kjxyl.ifzu.cn } \\
\text { http://9833.ifzu.cn } \\
\text { http://gjckyjs.ifzu.cn }\end{array}$ \\
\hline $\begin{array}{l}\text { independently developed } \\
\text { multi-functioned service } \\
\text { and management } \\
\text { platform }\end{array}$ & $\begin{array}{l}\text { Virtual simulation experimental platform of role } \\
\text { ability chain } \\
\text { Fuzhou University Sandplay association. }\end{array}$ & $\begin{array}{l}\text { http://eavs2.ifzu.cn } \\
\text { http://fzusp.ifzu.cn }\end{array}$ \\
\hline
\end{tabular}

Meanwhile, it is also suggested that test accounts and its application procedures (if not established, sharing procedures should be built from the school level) and contacts are publicized on the platform. For example, by June of 2018, F University's website has received over 1.2 million visits in total (more than 230, 000 visits this year) and opened more than 10000 on-campus accounts and more than 
1000 out-of-campus accounts, with more than $10 \%$ of out-of-campus sharing; besides, similar platform (of the same or similar disciplines) websites can also be added to increase the visit turnover.

\section{Summary}

Under the general trend of promoting educational resources sharing with the internet, the sharing situation of educational resources in China also takes many forms. It is found that VSET platforms has a low sharing level and unclear sharing channels. Therefore, information regarding VSET platforms are collected from websites of the Ministry of Education, provincial educational departments and relevant schools by discipline, region and grade level to establish a experimental teaching cooperative cloud platform. The platform:

1) Displays the quick acccess function of platform integration and improve the sharing level of VSET platforms among universities.

2) Establishes a maintainable DOM set bank of platform website to facilitate the following platform collecting and expansion.

3) Explores sharing strategies for VSET platforms from both macro level (governmennt) and micro level (school), and identify an effective method for implementation.

4) Carries out detailed analysis taking the case of F University's VSET platform as an example, to demonstrate its operationality by establishing virtual teaching cooperative environment.

Additionally, university VSET platforms are seldom independently developed; they mostly rely on software suppliers and customized development. Therefore, supportive technicians are needed to carry out maintenance job, which may restrict the following platform expansion; besides, universities giving public accounts to access their VSET platforms are rare, and policies about mutual recognition of academic scores are also insufficient, these areas need to be further studied.

\section{Acknowledgements}

This work was financially supported by research project on major educational and teaching reform of university in Fujian Province (16JXGG01); special research topic on cross-strait occupational education 2016, the 13th five year plan for educational science in Fujian(FJJKHX16-053); Asset appraisal research topic of Fujian's social science research and planning base (JXY201801-05 and JXY201801-08); Major project funding for social science research base in Fujian province social science planning.

\section{References}

[1] He Zhankui,Huang Tao. Exploration on construction of virtual simulation experimental teaching project. Experimental Technology and Management,Vol.35(2018),p.108-111+116.

[2] Ji Zhou, Kai Wang, Xiulan Zhang, etc.The comparison between series and parallel: Integrated experimental teaching model for pharmaceutical engineering students based on criteria for accrediting engineering programs in China.Journal of Cleaner Production, Vol.172 (2018), p.4421-4434.

[3] Guillaume C.Approximate NORTA simulations for virtual sample generation.Expert Systems with Applications,Vol.73(2017),p.69-81.

[4] Hui-Min Lai, Yu-Lin Hsiao, Pi-Jung Hsieh.The role of motivation, ability, and opportunity in university teachers' continuance use intention for flipped teaching.Computers \& Education, Vol.124 (2018), p.37-50.

[5] Margaret Verkuyl, Jennifer L. Lapum An Exploration of Debriefing in Virtual Simulation Short communication.Clinical Simulation in Nursing, Vol.13(2017),p.591-594.

[6] Nick Rushby. The Future of Learning Technology: Some Tentative Predictions. Educational 
Technology \& Society, Vol.16(2013),p.52-58.

[7] Kwo-Chen Lee, Chin-Ching Yu,Yann-Fen Chao.Situated teaching improves empathy learning of the students in a BSN program: A quasi-experimental study.Nurse Education Today,Vol.64(2018), p.138-143.

[8] Zhang Hongxia, Research methods of education science, Beijing, Education Science Press, (2009).

[9] TEDI. About the flipped classroom[EB/OL]. [2015-12-15] http://www.uq.edu.au/teach/flipped-classroom/what-is-fc.html

[10] Chen Yukun and Tian Aili,Introduction on MOOC and flipped classroom, Shanghai,East China Normal University Press, (2014).

[11] Johnson, L., Adams Becker, S., Estrada, V. \& Freeman, A. (2014).NMC Horizon Report: Higher Education Edition[R]. Austin, Texas: The New Media Consortium.

[12] Cui Guanxun,Xiong Jianping.Development of platform in practical teaching for MOOE based on virtual simulation technology.Experimental Technology and Management,Vol.33(2016),p. 103-107.

[13] Liu ZHongkun, ZHao Qiang, Zhu Haishan,etc.The virtual simulation system for training and demonstrating the design of the head-end of spent nuclear fuel reprocessing.Annals of Nuclear Energy, Vol.108(2017),p.310-315.

[14] Hosam Al-Samarraie, Noria Saeed.A systematic review of cloud computing tools for collaborative learning: Opportunities and challenges to the blended-learning environment.Computers \& Education,Vol.124(2018),p.77-91.

[15] Lei Chaozi Education Informationization: from 1.0 to 2.0---direction and thoughts on developement of educational informationization in China in a new era academic journal of East China Normal University (education and science edition),Vol.36(2018),p.98-103+164.

Author: Lu Minrong (1981-), male, Fujian Zhangzhou;senior experimenter of Fujian Jiangxia College; master degree; field: data mining, application of computer, virtual simulation; Tel:18905900199,E-mail:1698030620181@fjjxu.edu.cn

Corresponding author: Pan Yan (1955-), Female, Fujian Fuzhou, professor of Fuzhou University, supervisor of Doctors; field: internal control and virtual simulation of Economy and Managemetn; Tel:15359189541, E-mail:fzdxpy@163.com. 